\title{
Sympathetic control of aqueous secretion in man
}

\author{
A. J. BRON* \\ WITH THE TECHNICAL ASSISTANCE OF MISS JANE THOMAS \\ Department of Clinical Ophthalmology, Institute of Ophthalmology, University of London
}

The use of adrenaline in the treatment of open-angle glaucoma has both clinical acceptance and experimental support. But the mechanism underlying its ocular hypotensive action is still poorly understood. The role of the sympathetic nervous system in the regulation of aqueous dynamics is also not clearly worked out for man, though our understanding has been greatly increased in recent years.

It is generally held that topical adrenaline in man lowers ocular pressure by a dual mechanism, reducing the resistance to aqueous flow on the one hand, and reducing the aqueous flow on the other (Garner, Johnstone, Ballintine, and Carroll, 1959; Becker and Ley, 1958; Becker, Pettit, and Gay, r96ı ; Sears, I966; Goldmann, I95 I).

Research in animals has suggested that the effect on the outflow resistance is mediated by the alpha action of adrenaline (Sears and Bárány, 196o; Eakins, I963; Langham, I965). There is both anatomical and physiological evidence for sympathetic innervation of both the ciliary gland and the outflow tract, though the extent of this innervation varies in different species (Ehinger, I966; Laties and Jacobowitz, I964; Holland, von Sallmann, and Collins, 1957). Stimulation of the cervical sympathetic nerve electrically produces a fall in aqueous flow in the rabbit, in association with a fall in ciliary blood flow (Langham and Rosenthal, ig64).

Given that sympathetic excitation has a pressure-lowering effect in the eye by its actions on outflow resistance and flow, it would be expected that sympathetic denervation would have the opposite effect. But chronic anatomical (Duke-Elder, 1932) or pharmacological (Keates, Krishna, and Leopold, r96o; Küchle, r96ı ; Stepanik, r96ı ; Oosterhuis, I962) denervation each produce a fall in ocular pressure though not of a great degree. This contradiction of expectations requires an explanation, for it implies that our assumptions about sympathetic function, in man at least, may be in error.

To investigate the problem, aqueous flow was measured by the suction cup method in two subjects with unilateral ocular sympathetic denervation. One was a patient with a clinical Horner's syndrome, and the other was a subject with a "pharmacological denervation" of one eye produced by topical guanethidine drops. Guanethidine is a sympathetic post-ganglionic blocking agent acting by preventing release of noradrenaline from the nerve stores in response to nervous stimulation. It causes initial depletion of catecholamine from the nerve fibre, blocks conduction, and prevents uptake of catecholamine into the tissue stores.

* In receipt of an Alexander Piggott Wernher Memorial Trust Fellowship granted by the Medical Research Council, England, and a Lister Travelling Fellowship granted by the Royal College of Surgeons, England for the period $1964-65$ Present address: Moorfields Eye Hospital, London, E.C.I

This work was done in the W. K. Kellogg Foundation Laboratories of the Alan C. Woods Research Building, Johns Hopkins University Medical School and Hospital, Baltimore, Maryland 


\section{Material}

Two subjects were investigated

(I) A man with left Horner's syndrome A 56 -year-old Negro presented in May, 1965, with $\stackrel{\overline{\bar{N}}}{+}$ a drooping of the left upper lid of 3 months' duration. He complained also of a dull ache in the lefte shoulder and supraclavicular region of 2-3 months' duration which occurred particularly in the early hours of the morning. The patient himself noted lack of sweating on the left side of the face There was a left Horner's syndrome with miosis and ptosis but no enophthalmos, and a palpable tender left supraclavicular node. Biopsy of this node showed a metastatic carcinoma of unknownes origin and further studies did not demonstrate the primary lesion.

(2) A man with pharmacological right Horner's syndrome A fit adult white man aged 29 years received topical guanethidine ro per cent. into the right eye three times daily for a total of I4 days. To prevent loss of drug through epiphora and to facilitate entry of the drug through the cornea, each drop of guanethidine was preceded by a drop of ophthaine (proparacaine). Studiest of aqueous flow were made in both eyes, before, and 6 days after starting the guanethidine drops. The drops were made up as an unbuffered solution of the sulphate in normal saline (Ciba Pharmaceutical Co.).

\section{Methods}

Aqueous flow was measured using the suction cup technique of Langham (1963). Most measure $\frac{0}{2}$ ments were made after a ro-minute application of suction, though in a few instances a 15 -minute period was used.

Catecholamine solutions for aqueous flow studies were made up in normal saline on the day of use. They were unbuffered, and comprised l-adrenaline as a $0 \cdot 1$ molar solution and a l-nor-0 adrenaline as a 0.5 molar solution. Both were made up as the bitartrate salt. The molar concen tration of the noradrenaline was made five times that of the adrenaline solutions because, in pupillary studies, adrenaline has been found to be more potent as an alpha stimulator than nor adrenaline, on an equimolar basis (Bennett, Reinke, Alpert, Baum, and Vasquez-Leon, 196r) Before aqueous flow studies, the eyes were anaesthetized with a drop of ophthaine (proparacaine) $\frac{3}{3}$ This minimized lacrimation due to stinging of the drops, and possibly increased penetration of catecholamine. The puncta were then blocked with petroleum jelly on each side, to ensure that little catecholamine was lost by lacrimal drainage immediately after installation of the solution Finally, $20 \mu \mathrm{l}$. catecholamine solution were instilled into each conjunctival sac, and the puncta were held away from the globe for 5 minutes. This small volume was used to lessen the chance of spillage It was hoped that by these measures equal amounts of catecholamine would reach each eye, an make the response of the two eyes comparable.

\section{Results}

\section{(1) Left Horner's syndrome}

A. LIDS A marked left ptosis was present. With the eyes in the primary position the maximum heights of the palpebral fissures were $15 \mathrm{~mm}$. right, and $10 \mathrm{~mm}$. left. The ptosis was variable and at times obscured the patient's vision as the lid passed across thew pupil.

Elevation of the left lid could be induced by topical adrenaline in an amount and con? centration which did not affect the normal lid. This is a manifestation of supersensitiza $\stackrel{\mathbb{N}}{\rightarrow}$ tion of the denervated Müller's muscle and is well recognized (Cogan, 1956).

B. OGULAR TENSION The applanation pressures were recorded on various days overo the period of study with a Goldmann applanation tonometer. For each eye the mean of twelve readings taken on seven separate days was I I $9 \mathrm{~mm}$. $\mathrm{Hg}$ right, and 9.4 $\mathrm{mm} . \mathrm{Hg}$ left 
c. PUPILs Pupil diameters were measured under standard conditions of illumination using the measuring graticule in the ocular of the Goldmann perimeter. The means of nine readings taken on seven separate days were $2 \cdot 9 \mathrm{~mm}$. right and $2 \cdot 2 \mathrm{~mm}$. left.

Pupillary activity Both pupils were mobile and active to light and the near reflex. The anisocoria diminished in bright light and was greatest in dim light. Although I : I,00o adrenaline, one drop $\left(5^{\circ} \mu \mathrm{l}\right.$.) in each eye, failed to dilate either pupil in ward conditions, a repetition of the test subsequently, following a tonography, elicited a mydriasis in either eye but brisker and of greater degree on the left. The measurements, using the graticule of the Goldmann perimeter, were as follows:

\begin{tabular}{lll}
\hline & \multicolumn{2}{l}{ Pupil diameter $(\mathrm{mm})}$. \\
\cline { 2 - 3 } Time after adrenaline (min.) & Right & Left \\
\hline 0 & 3 & 2.5 \\
15 & 4.5 & 5.5 \\
25 & 6.5 & 7.5 \\
\hline
\end{tabular}

Two further experiments confirmed a brisker response to adrenaline in the left eye.

These results were taken to indicate some supersensitization of the left pupillary dilator muscle.

In response to cocaine 4 per cent. in both eyes, both pupils dilated, the right more than the left, in clinic conditions.

\section{AQUEOUS DYNAMIGS}

Aqueous flow At least 3 days elapsed between a catecholamine test and the next resting flow estimation. The values obtained by suction cup were as follows:

\begin{tabular}{|c|c|c|c|}
\hline \multirow{2}{*}{ Day } & \multirow{2}{*}{ Comment } & \multicolumn{2}{|c|}{ Aqueous flow ( $\mu l . / m i n)}$. \\
\hline & & Right & Left \\
\hline I & Resting flow & $I \cdot 92$ & $1 \cdot 17$ \\
\hline 2 & Resting flow & $\mathbf{I} \cdot 55$ & Poor response \\
\hline 4 & Resting flow & $1 \cdot 54$ & $0 \cdot 80$ \\
\hline 4 & $6 \mathrm{hrs}$ after adrenaline $20 \mu \mathrm{l}$. both eyes $0 \cdot 1$ molar & $\mathbf{1} \cdot 76$ & $2 \cdot 07$ \\
\hline 7 & Resting flow* & Poor response & $1 \cdot 04$ \\
\hline 7 & $6 \mathrm{hrs}$ after noradrenaline* $20 \mu \mathrm{l}$. both eyes 0.5 molar & $1 \cdot 25$ & $\mathbf{r} \cdot 60$ \\
\hline 24 & Resting flow & $1 \cdot 75$ & $1 \cdot 47$ \\
\hline
\end{tabular}

* On these days the suction cup was applied for 15 minutes; on all other days for 10 minutes.

The mean resting flows (four values each eye) were $\mathrm{I} \cdot 7 \mu \mathrm{l} . / \mathrm{min}$. right and $\mathrm{I} \cdot \mathrm{I} \mu \mathrm{l} . / \mathrm{min}$. left; i.e. flow is lower in the eye with Horner's syndrome. The mean flows after catecholamine (two values each eye) were $\mathrm{I} \cdot 5 \mu \mathrm{l}$./min. right and $\mathrm{I} \cdot 8 \mu \mathrm{l} / \mathrm{min}$. left. More experiments with catecholamines were planned, but the patient was unable to attend further. 


\section{(2) Right pharmacological Horner's syndrome}

A. LIDS A right ptosis developed gradually on treatment topically with guanethidine. The Figure shows the lids in the $I^{\circ}$ position of gaze on the seventh day of instillation. $\vec{F}$ The right ptosis is well shown. It was possible to elevate the right upper lid to the level of the left by instillation of $20 \mu \mathrm{l}$. noradrenaline, $0.5 \mathrm{M}$ in each eye. The ptosis resumed in a few hours.

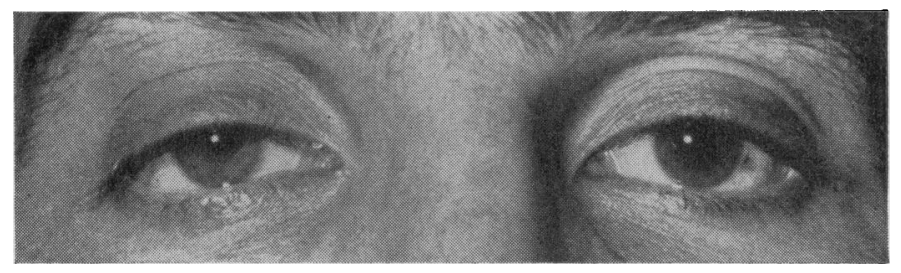

FIGURE Right ptosis following topical Guanethidine

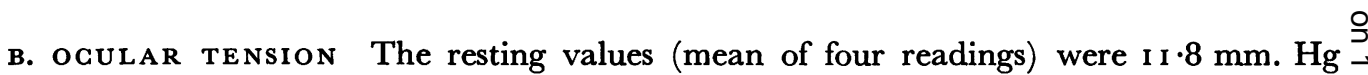
right and $10.8 \mathrm{~mm}$. $\mathrm{Hg}$ left.

After instillation of guanethidine ro per cent. into the right eye three times a day the mean of three readings was I $\cdot 0 \mathrm{~mm}$. $\mathrm{Hg}$ right and I $\cdot 3 \mathrm{~mm}$. $\mathrm{Hg}$ left.

c. PUPILS Guanethidine in the concentration used produced miosis within 24 hours. The pupil diameters on the seventh day of instillation were $2.8 \mathrm{~mm}$. right and $4^{\circ} \mathrm{Omm}$. left by Goldmann, standard illumination. On the twelfth day of instillation $20 \mu \mathrm{l} .0 \cdot 5$ molar noradrenaline were instilled into each eye. This produced little response in the left eye, and a marked mydriasis in the right eye. The pupil diameters 7 minutes after $\stackrel{\circ}{\mathbb{D}}$ noradrenaline were $8 \mathrm{~mm}$. right and $4 \mathrm{~mm}$. left by Goldmann, standard illumination. At 2 hours and 35 minutes they were $7 \cdot 0 \mathrm{~mm}$. right and $4 \cdot 1 \mathrm{~mm}$. left. The right pupil was still more dilated than the left at $6 \frac{1}{2}$ hours, equal to it at io hours, and smaller than the left at 14 hours. These findings were taken to imply supersensitivity of the pupillary dilator muscle on the side of guanethidine treatment.

The presence of a true, right miosis of sympathetic denervation was confirmed on the fifth day of instillation, by infra-red pupillography, which was performed in the laboratory of Dr. I. E. Lowenfeld of the Department of Ophthalmology, Columbia University, N.Y.

D. AQUEOUS DYNAMIGS

Aqueous flow before treatment with guanethidine

\begin{tabular}{llll}
\hline & & \multicolumn{2}{l}{ Aqueous flow $(\mu l . / m i n)}$. \\
\cline { 3 - 4 } Day & Comment & Right & Left \\
\hline $\mathbf{2}$ & Resting flow & $\mathbf{1} \cdot 8$ & $\mathrm{I} \cdot 73$ \\
3 & Resting flow & $\mathrm{I} \cdot 76$ & $\mathrm{I} \cdot 76$ \\
4 & Resting flow & $\mathbf{1} \cdot 75$ & $\mathrm{I} \cdot 97$ \\
\hline Mean of four consecutive days & $2 \cdot 45$ & $\mathbf{2} \cdot 05$ \\
\hline
\end{tabular}


After treatment with guanethidine ro per cent. three times a day to the right eye the values were:

\begin{tabular}{|c|c|c|c|}
\hline \multirow{2}{*}{$\begin{array}{l}\text { Days' treatment } \\
\text { with guanethidine }\end{array}$} & \multirow{2}{*}{ Comment } & \multicolumn{2}{|c|}{ Aqueous flow $(\mu l . / \min )}$. \\
\hline & & Right & Left \\
\hline 6 & Resting flow & $1 \cdot 41$ & $2 \cdot 62$ \\
\hline 7 & Resting flow & $0 \cdot 97$ & $2 \cdot 59$ \\
\hline 8 & Resting flow & $0 \cdot 70$ & $\mathbf{1} \cdot 72$ \\
\hline 8 & $3 \mathrm{hrs}$ after noradrenaline $20 \mu \mathrm{l} .0 .5 \mathrm{M}$ to both eyes & $1 \cdot 71$ & $\mathrm{I} \cdot 44$ \\
\hline 10 & Resting flow & $0 \cdot 94$ & $2 \cdot 16$ \\
\hline 12 & & $1 \cdot 29$ & $2 \cdot 5^{1}$ \\
\hline I I & $3 \mathrm{hrs}$ after noradrenaline $20 \mu \mathrm{l} .0 .5 \mathrm{M}$ to both eyes & $\mathrm{I} \cdot 88$ & $1 \cdot 57$ \\
\hline 13 & & $1 \cdot 12$ & $\mathbf{1} \cdot 90$ \\
\hline
\end{tabular}

48 hours elapsed between any catecholamine tests and further resting flow readings.

Mean of flows on 6 days (excluding catecholamine responses) while on guanethidine to the right eye was $\mathrm{I} \cdot 0 \mu \mathrm{l}$./min. right and $2 \cdot 25 \mu \mathrm{l}$./min. left.

Mean of flows on 2 days (after noradrenaline to each eye) was $1 \cdot 80 \mu l . / m i n$. right and I.5 I $\mu \mathrm{l} . / \mathrm{min}$. left.

It is concluded from this that:

(I) Guanethidine given topically reduces the aqueous secretion, as in the patient with Horner's syndrome in the sympathectomized eye.

(2) The exhibition of topical noradrenaline to the guanethidine-treated eye restores the aqueous secretion to a normal level.

E. conjunctiva The eye treated with guanethidine showed mild injection of the bulbar conjunctival vessels. It was also noted that the ischaemic ocular pain which follows topical instillation of noradrenaline lasted longer in this eye.

\section{Discussion}

Both the subjects in this study had unilateral sympathectomies. In the first patient this was probably due to an interruption of the left cervical sympathetic chain in the lower neck by tumour invasion or compression, and probably represented a pre-ganglionic (or second neurone) lesion. This is supported by the definite but lesser response of the left pupil to cocaine and the only moderate supersensitivity of the pupil to adrenaline. The subject presented with a typical Horner's syndrome.

The second subject had a pharmacological sympathectomy induced by topical guanethidine in the right eye. This drug produces a blockade of the post-ganglionic fibres (or third neurone) of the sympathetic, and the ptosis, miosis, and characteristic pupillary response seen in this subject was the same as that in clinical Horner's syndrome.

The acute effect of guanethidine treatment is the release of catecholamine from the post-ganglionic sympathetic fibre leading to partial depletion. To avoid confusing the effects of catecholamine release with those of sympathetic blockade, no studies of aqueous 
secretion were made in the first few days of instillation. It was assumed that by 6 days topical therapy a "chronic" pharmacological denervation would have been produced. $\bar{A}$ large body of literature exists which cites the ability of Guanethidine to induce supe sensitization of adrenergic nerve endings (Boura and Green, 1962; Green and Robsor 1965; Hendley and Eakins, 1965; Sneddon and Turner, i 967).

The main interest of this study has been to investigate the role of the sympathetic nervou system in the regulation of aqueous secretion. In both subjects aqueous flow was lower in the eye with the sympathetic lesion. The fact that both subjects showed decreased secre tion argues against any direct effect of guanethidine in inhibiting flow. These finding令 are in agreement with those of Swegmark (1963), who also showed a decrease in flow in $\overrightarrow{d_{0}}$ patient with Horner's syndrome on the side of the lesion. He was able to reduce aqueous flow in the normal eye by treatment with topical guanethidine. A fall in flow during topical guanethidine therapy has been demonstrated in man by a number of techniques tonography (Verdi and de Molfetta, I965), suction cup (Swegmark, I 963 ), and fluorometrīo (Anselmi, Bron, and Maurice, 1968). The finding of a reduced flow associated witb an interruption of the sympathetic nervous pathway does not fit in with conventional views on the sympathetic control of aqueous secretion. It is generally stated the sympathetic stimulation decreases aqueous flow. If this were true, then interruption of tonic sympathetic activity would be followed by a rise in flow. Even if there were no tonic sympathetic activity, then interruption would still not be expected to lowe $\overrightarrow{\mathscr{E}}$ the flow.

The findings in this study then, suggest that, in man at least, a decrease in or absence of sympathetic activity results in a fall in aqueous flow. The corollary of this is that sym pathetic stimulation of the ciliary gland should increase flow, and that there is normally $\frac{\$}{8}$ tonic action of the sympathetic nervous system on the ciliary gland, maintaining flow Evidence exists for such a tonic sympathetic activity in the eye: pupil (Duke-Elder, 1932) uveal vessels (Bill, I962), outflow tract (Sears, Mizuno, Gintron, Alter, and Sherk, 1966) As the sympathetic adrenergic mediator is noradrenaline, which has a powerful alpha but a small beta action, it seems reasonable to suppose that any excitation of aqueous flow. would be an alpha effect, particularly since an inhibitory action on flow is ascribed to the. beta action of adrenaline (Eakins, 1963).

After sympathectomy, particularly post-ganglionic but also pre-ganglionic (Langham r966), the denervated receptors become supersensitized to catecholamine. There is goo evidence to show supersensitivity to the alpha action of catecholamines. Supersensitivity is also found in tissues after treatment with guanethidine (Green and Robson, 1965).

From what has just been deduced about sympathetic action on the ciliary gland, i would be predicted that stimulation of the supersensitive alpha receptors of the ciliar㡴.

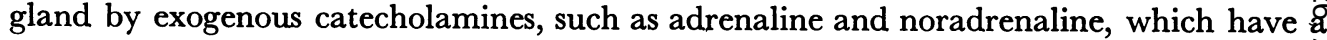
high alpha potency, would effect an increase in flow.

In keeping with the hypothesis, both subjects showed an increased aqueous flow ifi response to topical catecholamine (adrenaline and/or noradrenaline) on the side of the sympathectomy. A similar observation has recently been made in Horner's syndrome (Langham and Weinstein, I967). It is suggested then that the alpha or excitatory actiof of catecholamines on the ciliary gland is to increase flow, for if the effect had been othero than an alpha one, the eyes would not have shown a difference in response on the norma and sympathectomized sides (the idea that beta receptors may become supersensitize $\$$ following sympathectomy has recently been advanced, however (Schaeppi and Koella 1964; Langham and Fraser, 1966)). 
Such a concept at first sight appears to contradict both animal and clinical experimental observations which have demonstrated a fall in aqueous flow in normal or glaucomatous eyes, in response to adrenaline. But in fact no contradiction exists, if it is recalled that a reduction in flow is regarded as a beta effect (Eakins, 1963).

It may be postulated that both alpha and beta receptors exist in the ciliary gland and that the effects of stimulation of these receptors, on aqueous flow, are antagonistic, the alpha action being excitatory and leading to increased aqueous formation and the beta inhibitory and leading to decreased formation. The net effect of any catecholamine on aqueous flow would then depend on whether the alpha or beta stimulus predominated. In the present study only adrenaline and noradrenaline with their powerful alpha actions were used. Their molar concentrations were adjusted in an attempt toequalize their alpha effects.

In the sympathectomized eyes, supersensitization would greatly favour the alpha action on the ciliary gland above the beta action, particularly in the presence of an already low flow. Thus an increased aqueous flow is anticipated and found in this situation (despite the large beta stimulus presented in the case of adrenaline.)

In the normal eye it is assumed that a tonic sympathetic activity (mainly an alpha stimulus mediated by the transmitter noradrenaline) maintains flow at a level above basal. Further increase in aqueous secretion in response to alpha stimulation by exogenous catecholamine would be limited by the maximal response of the gland. In this situation the inhibiting beta action of the exogenous catecholamine would be favoured and a fall in flow would occur. This would be in keeping with previous observations on flow (Goldmann, 195I).

The above hypothesis might explain differences in clinical observations on flow in different circumstances; thus Galin, Baras, and Glenn (1966) found no change in flow in response to adrenaline in a long-term study, whereas Drance (1966) found an increase in flow in a short-term study. Both studies used suction cup analysis to determine flow, but it is likely that the concentrations of adrenaline entering the eyes in the two studies were different. The hypothesis would explain well the failure of guanethidine to potentiate the pressure-lowering effects of adrenaline (Drance, r966). Presumably in this situation, any beneficial effect on outflow resistance is counteracted by a rise in aqueous flow.

\section{Summary}

Aqueous flow has been measured by the suction cup method in two subjects with unilateral sympathectomy. One subject exhibited a clinical Horner's syndrome due to a lesion of the pre-ganglionic sympathetic fibres in the neck, the other a pharmacological sympathectomy induced in the eye by topical guanethidine drops over a period of time. The presence of the sympathetic lesion in the affected eye was confirmed by diagnostic tests, and during the period of aqueous flow measurement these eyes were assumed to be chronically denervated.

Both subjects showed a reduction in aqueous flow on the side of the sympathectomy, and both subjects showed a subsequent rise of flow on this side after treatment with topical catecholamine (adrenaline and/or noradrenaline). A tentative hypothesis has been put forward on the basis of these simple qualitative findings, in an attempt to explain the action of the catecholamines and of the sympathetic nervous system on aqueous flow in man.

The sympathetic adrenergic transmitter substance is noradrenaline, which has marked alpha effects and slight beta effects. After sympathectomy, the aqueous flow falls and this is interpreted as due to an interruption of a tonic, mainly alpha stimulus to the ciliary gland. 
Sympathectomy leaves the postulated alpha receptors in the gland supersensitive to
eir natural stimulus, while the beta receptors probably retain their usual threshold to stimulation. The rise in flow in the sympathectomized eye following topical adrenaline्ञ (and/or noradrenaline) is best interpreted as a response to an alpha stimulus to the glando

It is therefore suggested that in man, the ciliary gland responds to the alpha action of the catecholamines by increasing flow, and to the beta action of the catecholamines bx decreasing flow. When these stimuli are acting together, the net effect on flow would depend on the relative effective strengths of the alpha and beta stimuli. It is suggested that sympathectomy favours an alpha response, and that in the innervated eye where there is already a high "alpha tone" due to noradrenaline release, the beta response is favoured $\vec{\omega}$ This latter would account for the finding of a fall in secretion in normal eyes in response tog topical adrenaline, which has a powerful beta action.

Though much further work must be done in man to test the above hypothesis, it is felf that it may provide a rational explanation for a large body of apparently conflicting dataju

My thanks are due to Dr. M. E. Langham for his helpful advice in the preparation of this manuscript.

\section{References}

ANSElmi, P., BRon, A. J., and maurice, D. м. (1968) Exp. Eye Res., 7, 487

BeGKer, B., and LEy, A. P. (1958) Amer. J. Ophthal., 45, 639

-, PETTIT, T. H., and GAY, A. J. (196I) Arch. Ophthal. (Chicago), 66, 219

BENNETT, D. R., REINKe, D. A., ALPERT, E., BAUM, T., and VASQUEZ-LEON, H. (I96I)

Ther., 134, I90

BILL, A. (I962) "Studies on Uveal Circulation and Aqueous Drainage". Abstracts of Uppsala”

Dissertations on Medicine. Almquist and Wiksell, Uppsala boura, A. L. A., and Green, A. F. (1962) Brit. F. Pharmacol., 19, 13

COGAN, D. G. (1956) "Neurology of the Ocular Muscles", 2nd ed., p. 177. Thomas, Springfield, Ill." DRANCE, s. (1966) In "Drug Mechanisms in Glaucoma: The Gilston Glaucoma Symposium"

ed. G. Paterson, S. J. H. Miller, and G. D. Paterson, p. 6o et. seq. Churchill, London DUKE-ELDER, s. (1932) “Text-book of Ophthalmology", vol. I: The Development, Form anc

Function of the Visual Apparatus, p. 560. Kimpton, London

EAKINS, K. E. (1963) J. Pharmacol. exp. Ther., 140, 79

EHINGER, B. (ig66) Acta physiol. scand., 67, Suppl. 268

GALIN, M. A., BARAS, I., and GLenN, J. (1966) Invest Ophthal., 5, 120

GARNER, L. L., Johnstone, w. W., BAllintine, E. J., and Garroll, M. E. (1959) A.M.A. Arch

Ophthal., 62, 230

Goldmann, H. (I95I) Docum. ophthal., 5-6, 278

Green, A. F., and RoBson, R. D. (1965) Brit. J. Pharmacol., 25, 497

hendley, E. D., and Eakins, K. E. (1965) 7. Pharmacol. exp. Ther., r50, 393

holland, M. G., SAllmann, L. von, and collins, E. м. (1957) Amer. J. Ophthal., 44, No. 4, pt 2N

p. 206

KEATES, E. U., KRISHNA, N., and LEOPOLD, I. H. (1960) In "Symposium on Guantthidine", p. 66

Ciba Pharmaceutical Products, Memphis

кüChle, H. J. (196r) Klin. Mbl. Augenheilk., 139, 224

LANGHAM, м. E. (1963) Exp. Eye Res., 2, 314

$-(1965) \quad$ Ibid., 4, 38I

(Ig66) In "Drug Mechanisms in Glaucoma: The Gilston Glaucoma Symposium”, ed. G

Paterson, S. J. H. Miller, and G. D. Paterson, pp. 29-38. Churchill, London and FrASER, L. K. (1966) Life Sci., 5, 1699 
LANGmam, M. E., and Rosenthal, R. (1964) Fed. Proc., 23, $5^{17}$

and Weinstein, G. W. (1967) Arch. Ophthal. (Chicago), 78, 462

LATIES, A., and JAcoBowitz, D. (1964) Invest. Ophthal., 3, 592

oosterhuis, J. A. (1962) Arch. Ophthal. (Chicago), 67, 802

SEARS, M. L. (1966) Invest. Ophthal., 5, I I 5 and BÁrÁNy, E. H. (1960) Arch. Ophthal. (Chicago), 64, 839

, mizuno, K., cintron, c., Alter, A., and sherk, T. (I966) Invest. Ophthal., 5, 312

SChaeppi, U., and koella, w. P. (1964) Amer. F. Physiol., 207, I4 I I

SNeddon, J. M., and turner, P. (1967) F. Physiol. (Lond.), 189, $20 \mathrm{P}$

STEPANIK, J. (196I) Klin. Mbl. Augenheilk., 139, I 74

SWEGMARK, G. (1963) Trans. ophthal. Soc. U.K., 83, 255

VERDI, G. P., and DE MOLFETTA, v. (1965), Minerva oftal., 7, I 